\title{
Entrevista a José María Izquierdo Arroyo, realizada por Mónica Izquierdo Alonso en Alcalá de Henares (Madrid), junio de 2014
}

\author{
Interview to José María Izquierdo Arroyo by Mónica Izquierdo Alonso (Alcalá de Henares, June 2014)
}

\section{Mónica IZQUIERDo Alonso (1), José María IZQUIERDo ARRoYo (2)}

(1) Universidad de Alcalá, monica.izquierdo@uah.es. (2) Universidad de Murcia, izarro@gmail.com.

\section{Resumen}

Entrevista a José María Izquierdo Arroyo, realizada por Mónica Izquierdo Alonso en Alcalá de Henares (Madrid) en junio de 2014, sobre su contribución a la Ciencia de la Información y, en particular, a la representación y organización del conocimiento. Se destacan sus aportaciones en la incorporación de conceptos y teorías de la lógica, la lingüísitca y la semiótica para mejorar la recuperación de la información mediante métodos semánticos.

Palabras clave: Entrevista. Organización del conocimiento. Representación del conocimiento. Lógica. Lingüística. Semiótica. Fundamentación interdisciplinar.

\section{Introducción}

José María Izquierdo es uno de los autores de referencia en la organización y representación documental del conocimiento. A través de su trayectoria académica e investigadora nos introduce en el estudio de la semiótica y el pragmatismo documental y nos invita a un diálogo continuo, desde miradas inter y transdiciplinares, con sus maestros y grandes interlocutores teóricos: C.S. Peirce, Ortega y Gasset, Kristeva, Hjemlslev, Barthes, Greimas, etc.

Una pregunta constante se dibuja a lo largo de su producción académica relacionada con el documento-signo: la relación entre semiosis, semiótica e indagación pragmática. $Y$ a ella intenta dar respuesta, a través de triángulos peirceanos y signos en acción vital, en sus razonamientos sobre la teoría del documento- signo; en sus estudios sobre la teoría de la representación (desde categorías lógicas y pragmáticas); y en la teoría pragmatista del conocimiento y organización/representación documental.

En esta entrevista José María nos invita a conversar con él y a participar de sus creencias y

\begin{abstract}
Interview to José María Izquierdo Arroyo by Mónica Izquierdo Alonso (Alcalá de Henares, June 2014) on his contribution to information science and, in particular, to knowledge organization and representation. The interview highlights his contribution to the integration of concepts and theories coming from Logic, Linguistics and Semiotics to improve information retrieval by semantic methodos.
\end{abstract}

Keywords: Interview. Knowledge organization. Knowledge representation. Logic. Linguistics. Semiotics. Interdisciplinary foundations.

Our beliefs guide our desires and shape our actions (C. S. Peirce)

experiencias en el mundo de la Documentación, desde un "nosotros" con posibilidades infinitas en términos de acción y generaciones...

Aproximémonos a la puerta de su pensamiento desde su perspectiva lógica, científica y filosófica y... también, por qué no, desde su faceta más humana a través de este género, la entrevista. Yo me posicionaré desde la línea de interlocutor e interpretante, con la mirada puesta en las semiosis posibles, haciendo emerger contextos en los que la semiótica documental se abra a nuevas acciones y realidades.

[Mónica] ¿Cómo fueron los primeros comienzos del desarrollo de la Documentación como disciplina en España, en la denominada escuela madrileña a inicios de los 80 ?

[José María] Entre los años 1975 y 1985, yo me encontraba ya en Burgos, simultaneando la docencia e investigación universitaria en Literatura y Crítica literaria, con la ultimación de mi tesis doctoral en lógica formal (lógica sumulista, en concreto).

Mi primer contacto intelectual con el mundo de la Documentación se produjo a través de la 
Teoría de la Comunicación que se estaba desarrollando entonces. Yo hice una revisión de esa teoría, por necesidades internas de mi tesis doctoral, y el término Documentación se me presentó allí en paralelo con los términos Información y Comunicación. Como digo, partí de este último término, pero no me quedé en él. Mi aproximación crítica trajo consigo la idea de una nueva palabra en el marco del mundo de las Humanidades: Transducción; término que tomé en préstamo (entonces) del mundo de la física electrónica. La Crítica literaria (una de las asignaturas que explicaba entonces a mis alumnos burgaleses de Filología Hispánica) y la propia metodología de la investigación de mi tesis doctoral me llevaron a ese, digamos, "descubrimiento" -que otros aplicaron después a los estudios específicamente literarios-. En cuanto a la Documentación propiamente tal, recuerdo que mi primer contacto con ese mundo se produjo desde la Documentación Literaria; incluso te podría decir el primer libro que despertó mi interés hacia esos estudios. Ello es fácilmente explicable, ya que por aquel entonces yo dirigía un Departamento de Literatura. Cuando un cierto día -a través del Profesor Félix Sagredo- cayó en mis manos la obra magna de Paul Otlet, encontré reunidas en ella varias de las orientaciones heurísticas que yo venía contemplando ya. Pero fue su lectura lo que me permitió detectar los vínculos de fundamentación científica y técnica existentes entre la Documentación (del belga), por una parte, y la Lógica y las Ciencias del lenguaje (Lingüística, Semiótica, Textología) por el otro. Dentro de ese mundo, yo me sentía como pez en el agua, porque mi formación me permitía aproximar conceptos y procedimientos procedentes de mundos aparente (y oficialmente) inconexos.

Lo de la "Escuela de Madrid" fue, más que un hecho, un eslogan o frase de "reto". Yo conocía el libro de Julián Marías con ese título (1959), referido a una escuela que - según él-, partiendo del pensamiento de José Ortega y Gasset, y en diálogo con Miguel de Unamuno, reunía trabajos filosóficos de pensadores como Morente, Xirau, etc. Recuerdo que, en el marco de un curso de Metodología de la Investigación Científica impartido en Santander en $1984-\mathrm{y}$ en el que intervinimos ambos- le lancé ese "reto" al Profesor José López Yepes para que, desde su status académico, promoviera el encuentro de aquellas personas - como el Profesor A. L. García Gutiérrez-, que por entonces manteníamos distintas aproximaciones a un fenómeno científico común, pero aquello se quedó en puro "reto". La que llamas "Escuela de Madrid" creo que nunca fue más allá del marco de dos instituciones: a) la inicial "Escuela de Documentación" y b) el órgano de publicación del Departamento complutense de Documentación: la revista Documentación de las Ciencias de la Información. Quizás deba añadir un tercer componente, muy ligado con el segundo: c) la Bibliografía específica de Documentación que por entonces utilizábamos, reducida y en su mayoría común. Por lo demás, creo que simplemente coincidíamos con nuestros trabajos en el espacio de un Curso organizado por "a)" o de una publicación aparecida en "b)", o bien -en relación con "c)"- por la convergencia de fuentes comunes y citas cruzadas en nuestros trabajos. Por lo demás, yo me mantenía en Burgos (hasta el 85), en Málaga (hasta el 89) y posteriormente en Murcia (hasta hace dos años). Con todo, dos de los profesores mencionados y yo mismo procedíamos inmediatamente de ámbitos universitarios humanísticos: López Yepes y yo, de departamentos de Literatura; Félix Sagredo, de un departamento de Historia. La siguiente generación estuvo integrada ya por alumnos de ellos en la Facultad de Ciencias de la Información y por profesorado de otra procedencia. En rigor, mis encuentros oficiales con ellos fueron más bien ocasionales, aparte de mi bien conocida amistad con el Profesor Sagredo. Éste, con quien publiqué varios trabajos en Documentación, fue mi enlace permanente con Madrid. Pero, insisto, "Escuela" propiamente tal no hubo. La que he llamado "siguiente generación" trabajó ya en la diáspora...

[Mónica] ¿Qué te Ilamó la atención desde una perspectiva teórica? ¿Cómo fue tu acercamiento a esa nueva disciplina? ¿Cómo fue ese diálogo entre tu formación lógica, tu investigación lingüística en el departamento de Literatura y Crítica literaria y la Documentación; la Lingüística Documental. ¿Qué hay en esa transferencia de saberes?

[José María] La Teoría de la Documentación fue mi primer contacto con el mundo de la Documentación, y fruto de él fueron un libro y algunos artículos. En esa perspectiva teórica por la que me preguntas, yo me encontré con la referida obra magna de Paul Otlet, a mi entender bien sistematizada — para la década de los años 30-, y con las teorizaciones del Profesor López Yepes. Dentro del mundillo de la investigación -que en Burgos no coincidía, por mi parte, con el de la docencia - yo trabajaba en un ámbito (Lógica y Filosofía de la Ciencia) en el que el rigor era la virtud de la que más se presumía. Observé que se utilizaban algunos conceptos no muy bien definidos, que había ciertas lagunas y ausencias en la sistematización (coordinación), así como pasos un tanto gratuitos en la fundamentación de algunos conceptos y doctrinas. 
Sin duda que ello se debía a que se trataba de un cruce de disciplinas en el que muchas veces los autores carecían de bases específicas para algunas de ellas, o bien no habían llevado su documentación más allá de las fuentes inmediatas o de divulgación. Mi propósito era definir inequívocamente el ámbito de estudio para la teoría y la praxis de la Documentación, al tiempo que pretendía avanzar un poco en la estructuración (división) de esos conceptos y doctrinas. Mi acercamiento sólo podía hacerlo desde donde estaba yo en el momento en que cayó en mis manos el repetido libro de Otlet. Instalado en la Filosofía del Lenguaje (de corte más bien analítico) y en la Semiótica -acababa de leer a Peirce-, consideré que la aproximación más adecuada sería la lógico-lingüística (término éste que ya empezaba a aparecer en algunas publicaciones recientes de entonces). A ello obedeció el título y orientación del libro Concepción lógico-lingüística de la Documentación. Esa primera tarea la acometí en Burgos, en simultaneidad con mi docencia en Literatura y Crítica Literaria, y fue como chocar dos pedruscos de pedernal o sílex. Buscaba con ello que saltara una chispa que me permitiera iluminar el nuevo ámbito: el uno de los pedernales, la Lógica (tanto "material" como "formal"), y el otro la Lingüística - "sensu lato", (ya que en mi aplicación se recurría también a la llamada Ciencia del Texto)- En cuanto a lo de la LD (Lingüística Documental), he de decirte que eso vino después. Cuando decidí cambiar de área de conocimiento y "saltar" de Málaga (Lógica y Filosofía de la Ciencia) hacia los nuevos estudios de Murcia (Biblioteconomía y Documentación), se me propuso opositar a una nueva asignatura, la Lingüística Documental; a la que acababa de bautizar con ese nombre el Profesor A. L. García Gutiérrez, dentro de un libro muy importante aparecido un año después del mío $(1983,1984)$. Tuve que reunir y sistematizar los contenidos de la nueva disciplina, y lo hice en los tres tomos de los "Esquemas de Lingüística Documental" (1989-1990); redactados en Málaga, una vez dejada ya atrás la Lógica "académica", entre clase y clase de Historia de la Filosofía y Estética en la Facultad de Filosofía y Letras. Pero el hilo conductor de mi propuesta era ya la Semiótica peirceana. Para la elaboración del trabajo Sobre la Transducción, había reunido en Burgos bastante material de Semiótica y Semiología. Autores como Charles S. Peirce, Charles Morris, Roland Barthes, A. J. Greimas, Julia Kristeva y otros me ayudaron mucho a la hora de tratar de verter aquel "vino viejo" en odres nuevos... A la LD, por razones de fundamentación y de expansión (incluso profesional), siempre preferí denominarla Semiótica Documental.

¡Buena pregunta, ésa de la "transferencia de saberes"! La transferencia es la acción de transferir: de trans-ferre, - $-\mathrm{y}$ éste de "trans" y "fero"-, llevar a través o a lo largo de... Así pues, toda transferencia de saberes es, en realidad, lo que yo llamaría una transducción doctrinal. Se llevan conceptos, doctrinas y métodos de un lugar o disciplina a otro. Ahora bien, en toda transducción (en todo "transductor") las señales en la salida del sistema sólo son análogas a las señales de entrada en él; lo que significa que las señales en parte son iguales, pero distintas en una mayor proporción. Para que esto se entienda mejor, te pondré un ejemplo: las señales que entran en un micrófono (que es un "transductor") son de naturaleza acústica, mientras que las que salen de él son ya de naturaleza electromagnética; $y$, sin embargo, el mensaje decimos que es "el mismo". En el caso que nos ocupa, el términus a quo de la transferencia de saberes eran las disciplinas humanísticas que vengo mencionando, y el términus ad quem, estaba constituido por las disciplinas documentales. La señal de salida aquí eran ya - digamos - otros modos de ver las "cosas documentales". Esos nuevos modos de ver las cosas -"modi res considerandi" en el decir de don José Ortega y Gasset-quizás no fueran tan sencillos y claros como los que precedieron a la transferencia, pero, aunque más complejos, también debieron de ser más rigurosos y prometedores. En mi opinión, el legado de las Humanidades - adensado en la Semióticafue algo así como un punto de apoyo para que funcionara la palanca. Creo que esa máquina fue eficaz y con ella logramos "mover" un poco hacia delante las referidas "cosas documentales". Pero dejémonos de "filosofías": en la transferencia hubo una cierta dosis de innovación; salvando los imperativos académicos de mantener la tradición... Porque a pesar de utilizarlo en prácticamente todos mis trabajos, no logré, por ejemplo, introducir el término "Semiótica Documental" en los planes de estudios de Murcia.

[Mónica] Con una sólida formación en Filosofía y una marcada trayectoria lógicolingüística en Documentación, ¿cuáles han sido tus referentes teóricos aplicados a tus teorías y modelos en Documentación?

[José María] Del lado de la Documentación, me movieron algunas ideas redundantes en $P$. Otlet, J. Chaumier, M. Coyaud, Y. Courrier, M. Taube, J.C. Gardin, S. R. Ranganathan, D. J. Foskett, B. C. Vickery, D. Austin, De Grolier, Fugmann, I. Dahlberg y otros. Del lado de la formación en Filosofía, creo que puedo señalar 
tres referentes destacados, si bien menos conocidos en el ámbito documental: a) la "Grammatica Speculativa, sive De modis significandi", atribuida al Pseudo-Scoto/Tomás de Erfurt entre otros tratados de semiótica medieval-; b) los escritos lógico-semióticos de Charles Sanders Peirce (el mejor conocedor de esos tratados medievales dentro del área anglosajona); y c) el pensamiento perspectivista de don José Ortega y Gasset. Tendría que detenerme aquí más de lo prudente para explicar el primero, y en algún otro momento y lugar habré de hacerlo. Anteriormente he aludido a esa que llamas "trayectoria lógico-lingüística". Ahí es más difícil señalar autores como referentes teóricos concretos. Con todo, he de reconocer que mi "fórmula concepcional" contrajo deudas con la gramática generativa de A. Noam Chomsky — del lado de la Lingüística-; así como con el concepto de faceta - presente en algunos de los autores arriba mencionados- del lado de la Documentación. Pero también me serví de varios libros del Organon de Aristóteles y algunos de sus comentaristas, especialmente en lo relativo a la teoría de las Categorías y de los Predicables porfirianos; pues mi aproximación a las Ontologías echaba sus raíces en una relectura de algunos de esos libros. Precisamente mi primer trabajo universitario - la tesina de Licenciatura en Filosofía por Salamanca- versó sobre la ontología y sistema categorial del filósofo alemán Nikolai Hartmann. Los referentes en las Ciencias del Lenguaje son más vastos. Entre ellos se encuentran algunos de los que ya he mencionado: Greimas, Todorov, Barthes, Kristeva, Derrida..., pero también Louis Hjelmslev, J. Lyons, Karl Bühler, Roman Jakobson y algunos de los formalistas rusos. Como autorpuente entre el dominio de la Lingüística y el de la Documentación —en la especialidad de los "lenguajes documentales"-, he de resaltar el influjo que recibí de un discípulo directo de André Martinet: Maurice Coyaud. Su libro "Introduction a l'étude des langages documentaires" (1966) orientó mi integración del legado lingüístico en la LD. En general, aquí me ayudó bastante el estudio del acopio de materiales para la asignatura Crítica Literaria -que impartí en Burgos-y para mi trabajo "Sobre la Transducción".

\section{[Mónica] ¿Cómo fue el salto de la Lingüística a la Semiótica Documental?}

[José María] El tránsito doctrinal lo explico en varias páginas del tomo primero de mis Esquemas de Lingüística Documental (ELD) y, con mayor detenimiento, en el Epílogo que escribí para el libro del Profesor J. A. Moreiro G. En cuanto al tránsito académico —o la realización en las aulas- de ese "salto", he de decir que, hablando con propiedad, no se dio en el tiempo histórico; pues siempre fue más un ideal de aproximación, por mi parte, que un efectivo académico. Cierto es que la Semiótica Documental estuvo siempre presente en mis clases de Lingüística Documental; a lo largo de los sucesivos planes de estudios que tuvimos en la Universidad de Murcia en un período de veintitrés años (1989-2012). Cierto que en el primer plan de estudios pude dedicarle varios "Seminarios de Estudios", y que -en no más de tres cursos- estuvo presente en la asignatura optativa "Aspectos lógico-lingüísticos de la Documentación". También creé y mantuve el grupo de investigación de la Universidad de Murcia denominado SemioDoc (abreviatura de "Semiótica Documental"). Varios de los trabajos realizados con otras personas se "cocieron" dentro de ese Grupo. Pero insisto: fue más un propósito que un logro académico. Con todo, acontecimientos históricos tales como el predominio de la documentación soportada en la imagen audiovisual y los multimedia han logrado, de hecho, que la perspectiva meramente lingüística (en sentido estricto) se quede alicorta desde el punto de vista teórico, metodológico y práxico. Dejo ahí el reto de una evolución de la perspectiva Lingüística hacia la perspectiva Semiótica, en todo el ámbito de la Documentación; y no sólo en el dominio de la LD. He dejado escrito que es preciso cambiar tanto el objeto formal de la disciplina (ampliándolo), como los procedimientos analítico-sintéticos de la misma. Tal y como posteriormente hemos visto en escritores como Hjörland, será cometido de otros el hacerse eco académico de esos propósitos.

He dicho antes que la Semiótica Documental estuvo siempre presente en mis clases. Lo estuvo de un modo especial en la metodología utilizada, ya que apliqué los métodos semióticos en las conceptualizaciones (definiciones y divisiones/clasificaciones) de las disciplinas académicas explicadas. Así, por ejemplo, en mi "clasificación facetada de los lenguajes documentales" echo mano de diez parámetros de clasificación de carácter semiótico, con sendos "binomios de opuestos": 1) enciclopédico/especializado, 2) alfabético/sistemático, 3) a priorila posteriori, 4) por extracción/por asignación, 5) libre/controlado, 6) analítico/sintético, 7) temático/facetado, 8) precoordinado/postcoordinado, 9) suelto/ligado, y 10) asintáctico/sintáctico. En otros contextos, manejé otros binomios semióticos, tales como los más conocidos: 11) uso/mención, 12) tipo/muestra (type/token), 13) tópico/coment(ari)o, 14) tema/rema, 15) foco/ presuposición, 16) isotopía/heterotopía, 17) 
coordinación/subordinación, 18) determinable/determinante, 19) patente/latente (superficial/profundo), 20) explícito/implícito (expreso/ tácito), 21) primitivo/derivado, 22) simple/compuesto, etc. En esta metodología semiótica, los parámetros utilizados adoptan la modalidad de los binomios de opuestos y funcionan como los clasemas utilizados en el llamado "análisis sémico" (de Portier-Greimas).

\section{[Mónica] ¿Cómo habría de ser la formación investigadora en Tratamiento temático de la información- Análisis Documental de Conte- nido?}

[José María] Yo prefiero hablar de tratamiento - Tratamiento Documental de Contenido (TDC) —, a hablar de análisis (ADC); justamente porque el enfoque metodológico ha de echar mano tanto del análisis como de la síntesis. Creo que el privilegio que en el ámbito académico ha tenido el AD frente al TD se ha traducido en algunos centros docentes en un estancamiento - cuando no ausencia- de la dimensión sintética: condensación y resumen. Ello ha provocado también la separación nociva de ambos tratamientos complementarios: el análisis (predominante en la indización o "descripción característica”) y la síntesis (más presente en el resumen o "descripción substancial"). En tu pregunta, has utilizado el adjetivo "temático". Yo prefiero hablar de tratamiento "documental". Digo esto por dos motivos: $1^{\circ}$ ) Porque el tratamiento temático de los documentos también se realiza en disciplinas que nada tienen que ver con la Documentación; así, el historiador de la Filosofía puede analizar los fragmentos presocráticos de Protágoras siguiendo la pauta de un determinado o determinados temas: el relativismo, por ejemplo. Pero la perspectiva del documentalista es bien otra. $2^{\circ}$ ) Porque la norma ISO para la construcción y mantenimiento de los tesauros monolingües - por muchos capítulos censurable-, cuando se ocupa de la estructura global de esas herramientas documentales distingue entre la estructura (¡macroestructura!) temática y la facetada. Por esos motivos, prefiero hablar de tratamiento documental.

Hay otro aspecto relacionado con el anterior que también desearía destacar. Se trata, una vez más, del paradigma documental anglosajón, que puedo caracterizar como descriptivista; frente al paradigma otletiano. A éste lo llamaría yo generativista, si no fuera por la confusión que el adjetivo pueda traer desde la aportación chomskyana. Los tratadistas anglosajones consideran al documento como algo ya producido que tenemos que describir; y no ya como algo generable, que podemos producir. No se trata sólo de la descripción característica/substancial (indiza- ción/resumen) del documento como un hecho, como algo ya producido. Desde 1983, vengo defendiendo y reivindicando que la Documentación, -en sus dimensiones teórica, metodológica y práxica - ha de ocuparse no sólo de describir los documentos ya producidos, sino también de dar pautas para la generación o producción de documentos cualesquiera. Sucede aquí algo análogo a lo que nos enseña la historia reciente de la Lingüística: Se ha distinguido entre la lingüística europea o saussureana, de corte descriptivista, y la lingüística americana o chomskyana, de corte generativista. Chomsky insistió en que le interesaba -más que analizar el lenguaje como algo ya producido: describirlo- dar con las reglas que nos permiten producirlo, generarlo. Desde el punto de vista comunicativo, diríamos que Chomsky se propuso explicar cómo un emisor puede producir (codificar) frases hasta entonces nunca pronunciadas o escritas; y explicar cómo un receptor puede entender (decodificar) frases hasta entonces nunca oídas o leídas. Pues bien, lo que Chomsky pregunta sobre el objeto "frase" (que era el objeto formal de la Lingüística en su tiempo), eso es lo que el documentalista instalado en el paradigma otletiano se pregunta sobre el objeto "documento": cómo generarlo de modo que sea fácilmente "recuperable", no quedando enterrado dentro de las montañas de papeles que se escriben...; producir documentos debidamente estructurados en previsión de que han de ser recuperables - en todo y en parte-, por un destinatario fingido o verdadero.

Este segundo aspecto que puede parecer un tanto al margen de tu pregunta está esencialmente relacionado con la dimensión analíticosintética del tratamiento documental del contenido (TDC). Analizar es descomponer un todo preexistente en sus partes constitutivas. Sintetizar es, sí, condensar, extraer lo substancial o esencial de algo, tomar su quintaesencia dejando a un lado los fárragos, resumirlo. Pero sintetizar es también producir algo no preexistente como un todo; algo así como en el laboratorio se sintetiza un compuesto de Química orgánica -El benzoato de metilo, por ejemplo-. ¡Eso se hace produciéndolo!

Dicho esto, creo que la formación de los investigadores en TDC exige una proyección interdisciplinar de la docencia. Ésta, a su vez, requiere para su diseño un estudio muy detenido de las disponibilidades académicas por parte de las adecuadas asignaturas transversales, con especificación de éstas y un estudio serio de sus relaciones mutuas: Lógica, Lingüística, Informática, etc. Por lo menos, todas aquellas contemplé ya hace veinticinco años en la lec- 
ción tercera de mis Esquemas de Lingüística Documental (ELD): "Demarcación externa: Cruce de disciplinas en la LD".

\section{[Mónica] ¿Qué papel tendrían la filosofía y las Ciencias de Leguaje en una investigación especializada?}

[José María] Esta pregunta tuya es, en gran medida, una continuación de la anterior. La Filosofía propiamente tal y bien entendida, que no la "académica", ha de estar presente en todas las ciencias y especialidades. Aporta una dimensión de profundidad y radicalismo a todas las preguntas e investigaciones. Más allá de los "datos" y de los "hechos", se cuestiona por los porqués y paraqués de cuanto nos rodea. La Filología y las Ciencias del Lenguaje aportan una dimensión complementaria de la anterior: Toda ciencia e investigación - sea especializada o generalizada- ha de expresarse con una terminología y construcción lingüística adecuadas, para sostener inequívocamente los conceptos y las doctrinas, las hipótesis y las tesis científicas (teorías). Tampoco esas dos aproximaciones están desvinculadas entre sí. La llamada Filosofía del Lenguaje sería un buen contraejemplo para su separación.

[Mónica] Ante los desarrollos de la web y la medioesfera, la convergencia de medios y plataformas, el nuevo papel activo del usuario como creador y consumidor de contenidos digitales, los transmedia y la comunicación digital interactiva, etc., y tomando como referente el nuevo ecosistema digital y documental y específicamente la Semiótica y nueva ecología mediática, ¿cuál es el papel de la Documentación, de la organización y representación del conocimiento?

[José María] En ese nuevo marco que tan bien describes, el papel de la Documentación ha de expresarse en nuevos retos emanantes de viejos principios. Algunos de esos principios los he ido formulando ya en mis anteriores respuestas. Insisto en la dimensión productiva de la Documentación. Insisto también en la dimensión interactiva (emisor-receptor) de los nuevos sistemas de Comunicación. Pero sigo llamando también la atención sobre el tercer término de la terna (1983): Información. No se confunda con lo que los filósofos llamamos Conocimiento. En una concepción personalista, es esencial la relación de un mensaje - "portador de información"- con la persona que lo produce y con la que lo reconoce. Es algo así como la verdad tomista, sostenida por dos entendimientos: el divino (verdad ontológica) y el humano (verdad lógica); entre quien lo crea y quien lo conoce. Pero el filósofo sabe que sólo un conocimiento verdadero es "verdadero conocimiento"; mientras que una información que es falsa no por ello deja de ser información.

Hecha esa aclaración somera sobre el concepto de "conocimiento", me preguntas por el papel de la Documentación en su organización y en su representación. Yo he aludido en alguno de mis trabajos a la relación complementaria existente entre la representación y el reconocimiento. A una Teoría de la Representación le corresponde una Teoría del Reconocimiento. El aserto es tan fácil de entender como la complementariedad existente entre la codificación y la decodificación en todo sistema comunicativo; pues representamos el conocimiento en un determinado mensaje, para que nuestro interlocutor o destinatario pueda reconocerlo adecuadamente. Pues bien, ya he sugerido arriba que uno de los papeles de la Documentación en el paradigma otletiano- es producir adecuadamente los documentos o controlar eficazmente su producción, y añado ahora que esa adecuación y eficacia dependen de cómo se organice el mensaje que representa el conocimiento.

Con todo, ya en 1983 llamé la atención sobre una actitud, en exceso racionalista, que reduce todos los contenidos documentales a conocimiento. El conocimiento es sólo uno de los ámbitos del contenido documental; y me inclino a pensar que no es precisamente el más importante. De modo análogo, la "función representativa" o cognitiva (Roman Jakobson) es sólo una de las funciones del lenguaje. Los documentos son portadores de otros valores distintos de los cognitivos y epistemológicos. Contienen también los documentos la expresión de los sentimientos (función expresiva) -recuérdense los valores estéticos- y las pautas, exhortaciones y órdenes (función inyuntiva) - recuérdense los valores jurídicos-.

Preguntas también por la funcionalidad de los tesauros. Como es bien sabido, - dentro de los lenguajes documentales de estructura combinatoria- los tesauros documentales, en su versión convencional, fueron inicialmente una salida provisional a los problemas que planteaban los lenguajes de "unitérminos" de Taube y el sistema de "descriptores" -e indización "por conceptos"- de Calvin N. Mooers. Pero esa provisionalidad se anquilosó con el tiempo, sentó cátedra, y las herramientas de los tesauros documentales convencionales se perpetuaron hasta nuestros días, a modo de panacea universal.

Durante varios años, dentro de la asignatura Diseño y Gestión de sistemas de Indización y Resumen documental (DGSIRD), realicé para 
mis alumnos una exposición y crítica sistemáticas de esas herramientas; pues incluso las normas internacionales sobre ellas $-\mathrm{y}$ no sólo las ISO- no resisten un análisis detenido.

[Mónica] ¿Consideras necesarios los tesauros como sistemas de representación y recuperación de información?

[José María] Sí que considero necesarios a los tesauros para esos propósitos documentales. Pero cuando digo "tesauros" me refiero a unos tesauros no-convencionales que reúnan por lo menos estas cuatro características: a) ser herramientas híbridas (combinatorio-sintácticas), b) de estructura facetada, c) perfectamente conectadas unas con otras en y entre los diversos dominios disciplinares en los que se aplican, y d) estar dotadas con operadores de agrupamiento -conectadores ("links") - e indicadores de función ("roles"), suficientes para evitar, en la recuperación de información, las llamadas "falsas combinaciones" que vienen produciendo los tesauros convencionales.

Subyace en tu pregunta el tópico de las funciones y usos de los thesauri. Creo que esas herramientas documentales, además de cumplir las funciones que les han sido tradicionalmente asignadas -en la indización y en la búsqueda de documentos (ya producidos)—, habrán de ser herramientas útiles en la producción documental de los documentos (aún no existentes).

[Mónica] ¿Hacia dónde, la evolución de los sistemas de representación documental?

[José María] Al igual que los sistemas de traducción automática, los dispositivos de indización -y muy especialmente los lenguajes de estructura sintáctica- quedaron paralizados allá por los años sesenta. Ello se debió, en gran medida, a que los ordenadores de entonces no estaban aún dotados de la velocidad de procesamiento y de la capacidad de almacenamiento masivo que requerían las tareas programables para esos propósitos: traducción/indización. Con el tiempo, se fueron superando esas limitaciones en el soft y en el hard de las máquinas, y la traducción automática logró resultados bastante satisfactorios. Pero no sucedió algo análogo con los Ilamados "lenguajes de estructura sintáctica". Tenemos "muy olvidados" a esos lenguajes; tanto los de "gramática simple" como los de "gramática elaborada". Y creo que no son incompatibles - sino simultaneables- con los lenguajes de estructura combinatoria. La integración de ambos es una tarea por realizar. Espero que la generación de los nuevos tesauros documentales resultantes de esa tarea se beneficie también con la investigación y puesta en marcha de esas mismas herramientas dispo- nibles ya en soporte digital y con funciones de interactividad y retroalimentación ("aprendizaje"). Un avance en la construcción e interacción de los actuales Tesauros-Ontologías podría ser un buen punto de partida.

[Mónica] Siempre has sido un visionario, ¿cuáles crees que son los desafíos actuales para la organización del conocimiento y los grandes retos futuros de la Documentación?

[José María] No acierto a adivinar en qué te basas para tildarme de "visionario". Fueron Otlet y Ortega - los dos grandes "santos de mi devoción"- quienes con toda razón merecerían ese calificativo. No jugaré a profeta ni agorero, pero el latido de la vena de positivismo comtiano contra la que siempre me he rebelado- me trae al recuerdo el conocido lema: "savoir pour prevoir, afin de pouvoir" (SABER para PREVER, a fin de PODER). El hombre, nos decía Ortega, se distingue del animal en que éste sólo "se ocupa", mientras que el hombre también "se preocupa". Es la preocupación lo que en nosotros dispara la previsión. Cuando, tras una adecuada información (savoir), estamos pre-venidos, nada de la realidad futura nos pillará "de improviso", pues estamos preparados para recibirla y darle con nuestra acción la respuesta adecuada. Pero vayamos a los que llamas "desafíos actuales", y empecemos por algo muy sencillo: Tenemos que aprender de nuestros propios errores. Nuestro pasado, las enseñanzas de la Historia - que se nos dan en ese reconocimiento- son el motor de arranque de nuestro saber sobre el futuro. Ahora bien, sabido es que a las "cosas de la Documentación" no les va últimamente lo que mejor en el ámbito de la enseñanza universitaria, y creo que hay que empezar por hacer un examen de conciencia en común interrogándonos por los porqués del fenómeno. A ese examen seguiría el reconocimiento de nuestros errores y, tras él -como diría el padre Gaspar Astete-, la contrición de corazón y el propósito de la enmienda. Pues sólo así vendrá una adecuada satisfacción de obra. Dirás que a qué viene este giro penitencial de mi respuesta. Pues, a pesar de nuestra inteligencia y nuestra razón - sucesoras del instinto animal, según se nos dice-, lo cierto es que avanzamos por ensayo y error: aprendemos de nuestros errores. Ahora bien, yo creo que en la década de los 90 fuimos con prisas excesivas en la creación de nuevos centros de estudio y Facultades; y nos dice el saber popular que nunca las prisas fueron buenas. Quizás la razón académica pesó más que la razón pura... Fuera lo que fuere la causa de esas prisas, creo también que por aquellos años se pensó más en la expansión y crecimiento en cantidad, que en la profundiza- 
ción y avance en la calidad. A falta de una solidez y consolidación de los fundamentos, bastó con que se desatara una ventolera, una crisis social generalizada —como la actual—, para que todo se fuera al garete...

Pero, al margen de la situación académica -en la que me vengo anclando-, me pides que mencione los "desafíos" actuales para la organización (adecuada) del conocimiento. Mira, me voy a centrar en dos objetos propios de la Documentación para los que su Ciencia Normal y paradigma dominante (asumiendo el sentido que Thomas S. Kuhn diera ya a esos dos términos) no tiene hoy una teorización y un tratamiento adecuados: $1^{\circ}$ ) el documento que se expresa en discurso ORAL, y $2^{\circ}$ ) el documento ICÓNICO ("sensu lato"), que es portador de o consiste en IMAGEN visual. El primero queda soportado en un archivo (analógico o digital) y su tratamiento documental (tanto su análisis como su síntesis) plantea problemas heurísticos para los que hoy por hoy no conocemos respuestas adecuadas. Piénsese, por ejemplo, en los miles o millones de kilómetros de cinta con grabaciones radiofónicas obrantes en los depósitos de RTVE. El discurso ORAL no es "recorrible" como "recorremos" el texto ESCRITO. Hoy por hoy, no podemos hacer una búsqueda directa sobre el discurso ORAL; de modo análogo a como Sí podemos hacerla sobre el texto ESCRITO. La búsqueda en la ORALIDAD sólo puede ser secuencial, recorriéndola "de pe a pa". No cabe el acceso directo a una palabra o expresión, ni muchísimo menos una organización de la ORALIDAD de un texto análoga a la concordancia (KWIC) de una expresión de búsqueda presente en un texto ESCRITO. Hoy por hoy, el procedimiento es sustituir el texto ORAL por el texto ESCRITO y, después, realizar las búsquedas $-\mathrm{y}$ demás tratamientos- sobre este último. El primer desafío actual que destaco es dar con procedimientos de tratamiento teórico, metodológico y práxico más directos. $\mathrm{El}$ segundo objeto propio de la Documentación que nos plantea hoy problemas es el que he llamado documento ICÓNICO. Cuando un documento está constituido por imágenes visuales -fijas o móviles-, su tratamiento queda, como he dicho, allende las competencias y posibilidades de la Lingüística. Pero aunque exista ya desde hace años- software para analizar una imagen en sus partes y realizar búsquedas de una de esas partes en un corpus de imágenes, eso sólo puede hacerse en dominios y ámbitos muy restringidos. Uno se emociona cuando observa que introduciendo un archivo de imagen en la banda de búsqueda de Google, puede recuperar imágenes análogas presentes en las páginas Web indizadas por ese motor de búsqueda. A veces, la cosa funciona bien, y uno profiere el ¡Eureka! de turno, pero hemos de admitir que el reconocimiento de la imagen para efectos documentales está tan en mantillas y es tan "primitivo" como el reconocimiento del discurso ORAL. Y esos son dos de los "desafíos actuales" que - atendiendo a su objeto- tiene hoy la Documentación.

Pero tú vas más allá y me preguntas por los "retos futuros". Mira, eso es imprevisible: La ciencia (entiéndase, la técnica) avanza que es una barbaridad; como diría Ortega, en los dos sentidos en que puede tomarse la palabra barbaridad: 1) "mucho"; y 2) "como Atila", esto es, arrasando con todo lo que encuentra a su paso, de modo que la tierra que se pisa no vuelva ya a crecer... Hace ya más de treinta años, en una nota del libro Concepción lógico-lingüística de la Documentación (1), señalé yo la posibilidad de que la información textual depositada en nuestros soportes físicos -entonces (1983) eran ya los discos ópticos- fuera "legible directamente por el cerebro humano".

En cualquier caso, creo que los "retos futuros" son los resultados de la solución que demos - a corto y medio plazo- a los "desafíos actuales", pero elevando esos resultados a un coeficiente exponencial... Aunque yo no lo veré ya, tengo confianza en los frutos del trabajo humano. La adecuada sementera de esos frutos dará el ciento por uno, y me asiste la esperanza de que el buen uso de los talentos recibidos haga más humanas, si cabe, a las personas.

\section{Notas}

(1) En la nota 700 , pág. 358 del referido libro se añadía: “La neurofisiología está aún en mantillas, y es imprevisible lo que la Biónica nos depara."

\section{Nota del editor}

Excepcionalmente, aunque negritas, subrayados y mayúsculas no se permiten como procedimientos de énfasis según las normas de la revista, se ha mantenido la tipografía original de la transcripción de la entrevista, por su alta expresividad y por su compatibilidad con otras obras de José María Izquierdo Arroyo.

Enviado: 2014-06-22. Aceptado: 2014-06-23. 


\title{
Procedimiento de evaluación
}

\author{
Evaluation process
}

\section{Introducción}

El procedimiento de evaluación en Scire es el de revisión por pares mediante el sistema de doble ciego - los revisores no conocen el nombre de los autores, ni viceversa- semejante al de otras revistas científicas, aunque tiene algunas peculiaridades que permiten ajustarlo a las condiciones específicas de su campo científico y de sus lectores.

\section{Objetivos}

El objetivo del procedimiento de evaluación es que se puedan admitir con rapidez los trabajos buenos, mejorar los que pueden ser susceptibles de aceptación -esto es, que, siendo interesantes, contienen errores o lagunas que deben ser corregidas - y rechazar los que no son adecuados para la revista por su tema o calidad, redirigiéndolos hacia otras publicaciones adecuadas o haciendo sugerencias al autor para la posible reutilización y reorientación de su trabajo.

El procedimiento de revisión tiene que tener en cuenta a los autores de los artículos que revisa, con los que el revisor debe intentar ser justo, pero también debe responder ante los lectores y los demás autores que compiten por el espacio de la revista, así como, de forma más general, con el proyecto editorial, la propia comunidad científica y el conjunto de la sociedad.

\section{Procedimiento}

Cada artículo requiere al menos la opinión favorable de al menos dos revisores y cada nota breve de al menos uno. Si el director de la revista estima que el artículo entra dentro de los objetivos de Scire —que se encuentran públicamente disponibles en cada número y en la página web de la revista-, lo envía a dos revisores - 0 , si es necesario, a más- elegidos por el director. Los evaluadores pueden ser miembros del consejo científico, revisores propuestos por los miembros del consejo científico con anterioridad o con motivo del artículo en cuestión, o científicos de reconocido prestigio propuestos por el autor o autores del artículo. La elección se hace según su conocimiento del tema y el número de trabajos que han evaluado hasta el momento (para equilibrar la carga de trabajo entre ellos).
Si el director estima sin lugar a dudas que el tema del artículo no se adecua al de la revista, se lo comunica al autor con una explicación suficiente, $y$, si le es posible, le sugiere otra revista que pueda ser más adecuada. De esta forma, se ahorra tiempo del autor y de los revisores.

La agilidad del procedimiento de revisión es un aspecto fundamental, por lo que el director solicita a los revisores que envíen su valoración en dos semanas, y que, en caso contrario, renuncien expresamente al proceso de revisión. Sin embargo, si el revisor no realiza ninguna de estas acciones, el proceso se retrasa sin remedio. En este sentido, el autor debe tener en cuenta que el proceso de revisión tiene un carácter voluntario. La decisión de aceptar el trabajo depende, salvo en casos excepcionales, de la opinión de los revisores. En los casos en que no están de acuerdo, la decisión es tomada por el director de la revista, que, excepcionalmente, puede decidir enviar el artículo a un nuevo revisor.

\section{Criterios de evaluación}

Se solicita a cada revisor que indique su valoración sobre los siguientes aspectos en una escala del 1 al 5 (1 muy cuestionable, 2 marginal, 3 suficiente, 4 sólido, 5 excelente):

1. Tipo de contribución: Se indica si se trata de una contribución de tipo teórico o metodológico, un estado de la cuestión, una comunicación de resultados de investigación, una experiencia específica, una exposición con valor introductorio o docente sobre el tema o una noticia de interés. Si es una mezcla de varios tipos, es posible marcar más de uno.

2. Adecuación del tema de la revista: Aunque al enviar el artículo al revisor el director de la revista ya ha realizado un juicio sobre su adecuación al enfoque de la revisa Scire, el revisor puede también valorar este aspecto, comparando el tema del artículo con la declaración de objetivos y alcance de la revista, disponible en cada número y en la página web.

3. Interés e importancia del tema: Grado en el que el artículo aborda una cuestión de gran interés para el área científica de Scire, ya sea tradicionalmente, en el momento actual o en el futuro previsible. 
4. Actualidad del tema: Grado en el que el tema se sitúa en los frentes actuales de investigación. No es un aspecto imprescindible, pero sí se considera informativo.

5. Novedad y originalidad teórica de la aportación: Grado en el que el artículo aporta una novedad teórica a su campo de investigación; esto es, un nuevo problema, un nuevo enfoque, un nuevo modelo, una nueva relación o ley, una nueva hipótesis, un nuevo concepto o una interpretación o modificación original de otros anteriores. Debe tratarse lógicamente de una aportación relevante y fundamentada.

5. Novedad y originalidad metodológica de la aportación: Grado en el que el artículo aporta una novedad metodológica a su campo de investigación; esto es, un nuevo procedimiento de estudio, de análisis o de prueba, aunque sea a un problema conocido.

7. Aplicabilidad práctica: Grado en el que las ideas del artículo pueden servir para la mejora de procedimientos y actividades prácticas y, en definitiva, para el desarrollo y la innovación.

8. Rigor metodológico y validez de los resultados: Grado de coherencia, exactitud, precisión y cuidado con el que se aborda el tema de estudio; validez y actualidad de la metodología utilizada; rigor en la selección de las muestras y en la aplicación de la metodología a las mismas; grado de replicabilidad del estudio.

9. Rigor en el estado de la cuestión y el reconocimiento del trabajo previo: Hasta qué punto se ha realizado un estado de la cuestión suficiente $y$ actualizado y se han manejado las referencias pertinentes para el problema abordado.

10. Claridad expresiva, orden y facilidad de lectura: El artículo debe estar redactado de forma clara y bien ordenada, sin redundancias ni ideas fuera de contexto; y debe ser fácilmente entendible por cualquier lector potencial de Scire. No debe faltar información necesaria ni deben existir lagunas sobre el problema abordado, el método, los resultados, la discusión, las conclusiones o las recomendaciones. Si el artículo contiene aparato matemático, debe ser comprensible por un lector no especialista.

11. Adecuación de gráficos, ilustraciones, tablas $y$ apéndices: Los gráficos, ilustraciones, tablas y apéndices deben ser necesarios y relevantes, estar bien resueltos técnicamente y disponer de una leyenda suficientemente explicativa.

13. Conformidad de las referencias a las normas de la revista: Grado en el cuál las referencias del artículo son suficientes y se conforman a las normas de la revista Scire.

\section{Familiaridad del revisor con el tema}

Aunque el director de la revista envía los artículos para su revisión intentando que coincidan con el campo de especialidad del revisor, pueden producirse desajustes. El revisor puede rechazar la revisión sugiriendo o no un revisor alternativo, o puede efectuar la revisión indicando de 1 (mínimo) a 5 (máximo) su grado de familiaridad con el tema del artículo evaluado. Si no rellena esta información, se entenderá que su grado de familiaridad es alto (4) o muy alto (5).

Esta información sirve para que el director de la revista pueda estimar la necesidad de enviar el artículo a un nuevo revisor en caso de conflicto de pareceres entre los revisores.

\section{Valoración final}

El revisor puede realizar cinco tipos de propuestas finales:

1. Aceptar el artículo para su publicación sin restricciones ni cambios, porque es un trabajo de alta calidad.

2. Aceptar el artículo para su publicación una vez realizadas las correcciones indicadas, bien sea incondicionalmente, al ser un trabajo de calidad, o bien de forma condicionada a que haya espacio disponible en el número, por ser un trabajo de calidad marginal. Las correcciones solicitadas se indican en las instrucciones para el autor, son de carácter menor y su comprobación puede ser delegada en el comité editorial.

3. Someter a reevaluacion el artículo una vez realizadas las correcciones indicadas en las instrucciones para el autor, porque son de importancia y amplitud, y deben ser comprobadas por el revisor original u otro revisor.

4. Rechazar el artículo por las razones indicadas en las instrucciones para el autor, donde el revisor especificará con claridad y amabilidad las razones por las que su trabajo debe ser rechazado y, si le resulta posible, realizará sugerencias sobre su mejora o lugares alternativos de publicación.

5. El revisor rechaza evaluar el artículo por su falta de familiaridad con el tema o por razones que especifica en los Comentarios confidenciales para el equipo directivo.

La labor de los revisores es fundamental para que una publicación científica realice su labor de manera adecuada. Scire agradece de forma muy especial el tiempo y esfuerzo que dedican, y reconoce su trabajo publicando periódicamente sus nombres. 